\title{
Moriscos e inquisición en Canarias durante el siglo XVI
}

\author{
ANDRÉs ACOSTA GONZÁLEZ
}

\section{LA POBLACIÓN MORISCA EN CANARIAS}

En el archipiélago canario, la población morisca, prácticamente en su integridad, procedía de las capturas de esclavos en Berbería. No así en la Península Ibérica, donde si bien existió una población morisca esclava, ésta fue mínima en comparación con la población morisca de raíz autóctona.

La diferencia entre ambas poblaciones moriscas era tal, que algunos autores dudan en abordarlas conjuntamente '. Pero hacia 1594, constatamos que ciertas disposiciones generales se aplican por igual para moriscos peninsulares y canarios. Así vemos cómo la orden general de empadronamiento de moriscos promulgada por la Inquisición, se hizo extensiva a Canarias ${ }^{2}$. Ello se debió a que a lo largo del siglo XVI, la afluencia de población esclava morisca al archipiélago no dejó de progresar. Por otra parte, una cierta proporción de moriscos iba consiguiendo su libertad y lograba insertarse en la población canaria realizando los más variopintos oficios.

En el tránsito de la Edad Media a la Moderna, la esclavitud descendió notablemente en Europa. Sólo en una zona, la periferia marítima mediterránea, perduró largamente el fenómeno esclavista. Ello se debió a dos factores fundamentales: la larga duración de la Reconquista, que hizo de las cabalgadas en Berberia una especie de prolongación de la

\footnotetext{
A. Domínguez Ortiz y B. Vincent: Historia de los moriscos, Madrid 1978, pp. 81-82.

2 Ibidem, p. 82.
} 
guerra santa, y el enfrentamiento con berberiscos y turcos a lo largo del siglo XVI.

El anterior razonamiento también vale para Canarias, pero con matizaciones. Los aborígenes guanches fueron reducidos a esclavitud muchos de ellos, pero no con el beneplácito de los conquistadores, que desde 1402 llevaban un firme propósito evangelizador. No obstante, las irregularidades fueron frecuentes. Muchos conquisiadores, gobernadores e, incluso, clérigos cometieron excesos. Pero no es este estudio sobre la problemática morisca el lugar adecuado para este análisis. Digamos, por último, que la decidida intervención de los Reyes Católicos en favor de los guanches canarios derrotados, hizo posible una pronta integración de la población aborigen canaria ${ }^{3}$. Ello hizo que la mano de obra necesaria para los trapiches de azúcar, menesteres domésticos, labores agrícolas y otros oficios duros, se obtuviese del continente africano. Moriscos y negros integraron fundamentalmente la población esclava canaria. Otro factor hemos de sumar a las causas anteriormente reseñadas: la colonización americana. Esta no sólo tuvo como protagonistas a los españoles que en grandes contingentes fueron arribando a tierras del Nuevo Mundo, sino también a numerosos grupos de esclavos, fundamentalmente negros.

Las capturas de moriscos en Berbería desde suelo canario, tuvieron lugar desde muy pronto, si admitimos como ciertas las entradas a que alude Abreu y Galindo ${ }^{4}$. Según este historiador canario del siglo XVII, la primera entrada que se hizo en Berbería desde el archipiélago canario, la realizó Juan de Bethencourt en 1405, capturando un buen número de moros, que luego vendería en España.

Pero cuando realmente fueron continuas y de envergadura las cabalgadas a Berbería en busca de esclavos moriscos o negros, fue a lo largo del siglo XVI. Ello se explica en base a que hasta finales del siglo XV no se conquistan las tres islas mayores, Gran Canaria, La Palma y Tenerife, islas donde se iba a producir un proceso colonizador intenso, y que iba a necesitar de una mano de obra numerosa.

3 A. Rumeu de ARmas: La política indigenista de Isabel la Católica, Valladolid 1969, p. 31; D. WÖLFEL: "La Curia romana y la Corona de España en la defensa de los aborígenes canarios", en Estudios Canarios, Hallein (Austria) 1980, pp. 1.011-1.083 y "Los gomeros vendidos por Pedro de Vera y Dña. Beatriz de Bobadilla", ibidem, pp. 5-84.

4 J. Abreu y Galindo: Historia de la conquista de las siete islas de Canaria, Santa Cruz de Tenerife 1977, pp. 69. 
A partir de 1572 decaen las incursiones en busca de esclavos moriscos ${ }^{5}$. Felipe II prohibió las cabalgadas por Real Cédula. $Y$ así se llegó a un acuerdo con los sultanes Abú Abdallah Mohammed, y sus inmediatos sucesores Abd el Mâlek y Abulâbbás Ahmed el Mansur, todos pertenecientes a las dinastías de los Xarifes. Pero como estos Xarifes no pudieron o no quisieron neutralizar las acciones piráticas de los berberiscos contra las islas, las cabalgadas volvieron a autorizarse en $1579^{6}$.

En 1493 toma posesión de su cargo el primer comisario del Santo Oficio en Canarias. A partir de este momento, la actuación del tribunal de la Inquisición no cesaría en el archipiélago hasta su desaparición en 1833. El primer inquisidor sería Bartolomé López de Tribaldos, y su instalación oficial, en Las Palmas, sede del tribunal inquisitorial canario, tuvo lugar en $1505^{7}$. En lo que a nosotros respecta, digamos que la fecha clave es 1504, pues es a partir de este momento cuando el tribunal de la Inquisición desencadena una gran actividad contra los moriscos, a los que pretende siempre encaminarlos por la senda de la fe cristiana ${ }^{8}$. Esta fecha de 1504 es la que da Lobo en el libro citado, mas no indica de donde la saca. Los documentos que yo he podido consultar en las fuentes clásicas (Archivo Histórico Nacional, Archivo del Museo Canario en Las Palmas, Catálogo Gray Birch, Historia de la Inquisición en Canarias, de Millares Torres), no aluden a ninguna causa de fe por Mahometanismo antes de 1510, y el número de causas de fe comienza a hacerse ya considerable en el quinquenio 1521/25. Es posible que Lobo aluda a esta fecha como la de la llegada del primer Inquisidor. Esta laguna no desmerece ni un ápice el extraordinario trabajo de Lobo que, por otra parte, aborda el problema de la esclavitud, y en ningún modo el de la Inquisición.

Frente a un primer período de hijos nacidos de parejas esclavas, período que va de finales del siglo $x \vee$ a 1522 , en un porcentaje elevado (se alcanza nada menos que un $31,6 \%$ en 1514), de 1522 a 1556 tiene lugar un primer descenso (se llega a un 12,4\%) y de 1556 a fin de siglo

${ }^{5}$ M. Lobo Cabrera: La esclavitud en las Canarias Orientales en el siglo XVI (negros, moros y moriscos), Las Palmas de Gran Canaria 1982, p. 56.

- A. RUMEU DE ARMAS: Piraterias y Ataques Navales contra las Islas Canarias, Madrid 1947, T. II. pp. $57-58$.

7 A. Millares ToRres: Historia General de las Islas Canarias, Las Palmas de Gran Canaria y Santa Cruz de Tenerife 1975, T. III. pp. 34.

${ }^{8}$ M. LoBo Cabrera: La esclavitud... op. cit. pp. 210. 
hay ya un gran declive de la natalidad esclava ${ }^{9}$. Esta evolución ha de contemplarse como una consecuencia lógica de las crecientes manumisiones. Muchos moriscos iban ganando la libertad, integrándose como familias normales en el seno de la sociedad canaria. De todos modos, la situación no era la misma en unas islas que en otras. Lógicamente, en las islas orientales, con unas características humanas y físicas más similares a la tierra continental inmediata, los moriscos se integraron mejor. En Tenerife, si bien el alto clero, la Administración y muchos comerciantes, compraron muchos esclavos en el mercado esclavista de Las Palmas, aquéllos nunca lograron ser bien vistos.

En líneas generales podemos definir a la población morisca esclava de Canarias como un grupo humano en el que predominaban aquellos sectores laboralmente más rentables en las faenas agrícolas y domésticas, lo que implica una debilidad numérica de población infantil y senil. Además, la duración media de la vida era muy baja, debido lógicamente al exceso de trabajo, insuficiencia alimenticia, médica e higiénica. La proporción entre mujeres y hombres resultaba favorable al sexo femenino: habia 72,3 varones esclavos por cada 100 mujeres de la misma condición. Pero esta proporción variaba mucho según el tipo de ocupación. El papel de la mujer era muy alto en el servicio doméstico. Ello ya nos indicà cuál era sin duda la función más frecuente de los esclavos: la servidumbre, pues constituía un claro símbolo de poder y prestigio social en las clases dominantes ${ }^{10}$.

Aun cuando, como ya hemos dicho, los moriscos fueron progresivamente ganando su libertad, e integrándose en la sociedad canaria, desempeñando diversos oficios, su relación con otros grupos sociales no siempre fue fácil. Por otra parte, la desconfianza de la Inquisición hacia ellos, a pesar de haber abrazado la nueva fe, nunca desapareció. Así vemos cómo en 1568 el inquisidor Ortiz de Funes logra sacar adelante una disposición por la que los moriscos, al menos en Las Palmas, debian vivir separados, en una especie de apartheid ${ }^{11}$. Hoy existe una calle en el barrio de Triana de Las Palmas, cuyo nombre es "calle Moriscos", recordando la zona donde la población morisca había de circunscribirse.

\footnotetext{
9 Ibidem, pp. 210-213.

${ }^{10}$ Ibidem, pp. 224-225.

11 A. Dominguez Ortiz y B. VICENT: Hist. ..., op. cit. pp. 82.
} 
Al igual que en Granada, en Canarias los moriscos fueron preferidos por sus dotes de transportistas en general, y de almocrebes (arrieros de mulos) en particular. Conocían muy bien a los animales de carga, sobre todo camellos. Además de estas cualidades como transportistas, poseian una singular destreza como ganaderos, y desempeñaban este trabajo en las islas orientales sobre todo, pues la proporción de población aborigen dedicada a estos menesteres, era escasa ya. Sin embargo en las islas occidentales, que habían sido conquistadas hacia muy poco, y en las cuales debido a esto, una alta proporción de población oriunda continuaba dedicada a labores de ganadería, los moriscos veíanse más relegados, obligados a desempeñar trabajos de inferior consideración social.

En los ingenios azucareros, los negros fueron sustituyendo poco a poco a los moriscos, ya que aquellos tenían por lo general más fuerza física y eran menos rebeldes. El aumento progresivo de capturas de negros así como la aparición y desarrollo del fenómeno del rescate (intercambio de un esclavo morisco, que así alcanzaba su liberación, por dos o más negros en Berbería), hicieron que los negros predominasen en muchos oficios: serrerías, trabajos agrícolas, peones albañiles y servicios domésticos (ambos sexos).

En algunos oficios de cierta especialización, predominaba el esclavo morisco, o el morisco liberado, sobre el negro. Así, por ejemplo, los prenseros, encajadores 0 bagaseros. Estos esclavos resultaban obviamente más caros ${ }^{12}$.

En cuanto a la edad que el esclavo debía tener para desempeñar su trabajo, no se conoce legislación que la regulara. Se tienen datos de esclavos de 13 años, e incluso de niñas esclavas de 4 años ${ }^{13}$.

Citemos como datos curiosos, que hacia finales del siglo XVI se detecta un apreciable aumento en la incorporación a los trabajos artesanales por parte de los esclavos moriscos, o que siempre la mayor importancia en número la tenían los esclavos y esclavas domésticos, siendo el estamento eclasiástico el que más adquiría. Casos de esclavas concubinas fueron muy frecuentes, así como muchos de prostitución, a fin de poder pagarse la esclava su libertad.

\footnotetext{
12 M. Lobo Cabrera: La esclavitud..., op. cit. pp. 235.

13 Ibidem, pp. 236.
} 
Las prohibiciones a que el morisco canario se vio sometido, fueron análogas a las que Felipe $\|$ promulgara en contra de los moriscos peninsulares: hablar su lengua, que la enseñasen a sus hijos, cantar, tañer panderos adufes (panderos moriscos) y biquelas, enterrar a sus muertos en el campo ${ }^{14}$.

El ciclo de toda esclavitud finaliza con la manumisión. Esta se alcanzaba, siempre que el dueño quisiera otorgarla, o siempre que el rey concediera escritura para liberar esclavos. Si era el dueño quien la otorgaba, la forma podía ser diversa: cláusula testamentaria o escritura, y en este último caso, podía producirse, bien porque el esclavo pagaba su libertad (caso muy frecuente) o bien por gracia. Lo que impulsaba a los reyes a conceder escritura para liberar esclavos, también podía tener diverso origen: que los propios hermanos de raza, ya libres, pleitearan ante la corte, o que, siendo los moriscos exclavos víctimas de tropelías, fuesen ayudados por los obispos, elevando éstos quejas ante el rey.

\section{CAUSAS DE FE CONTRA MORISCOS EN CANARIAS. UNA APROXIMACIÓN ESTADÍSTICA}

La actividad del tribunal inquisitorial canario en contra de los moriscos esclavos, así como en contra de aquellos no moriscos que se quisiesen convertir al Mahometanismo o infundiesen sospechas de herejía mahometana, tuvo una gran continuidad, mas no excesiva dureza. En el próximo apartado estudiaremos las condenas, y estableceremos una somera comparación con los castigos a otros herejes.

Si observamos las tablas generales ${ }^{15}$ con cierto detenimiento, extraemos dos conclusiones importantes:

a) A excepción del delito «Proposiciones Heréticas» y de algunos picos aislados de otros delitos («Protestantismo» a finales del

14 Libros de mandatos de Betancuria (Fuerteventura). Cita de M. LOBO CABRERA, en: La esclavitud..., op. cit. pp. 246.

${ }_{15}$ Tablas y gráficos extraídos de: Andrés ACOSTA GONZÁLEZ: «La Inquisición en Canarias durante el siglo xVI, en AEA (Anuario de Estudios Atlánticos), $n .^{\circ} 32$, Madrid y Las Palmas de Gran Canaria 1986. 
siglo XVI y "Hechicería» en 1521-1524), las causas de fe por Mahometanismo son las más abundantes.

b) Junto al delito "Proposiciones Heréticas", resulta el "Mahometanismo» el más uniformemente perseguido a lo largo de todo el siglo XVI en Canarias.

En este trabajo he desglosado las condenas por Mahometanismo en diferentes subtipos (tabla A), añadiendo nuevas causas de fe, recogidas en mi reciente visita al Archivo del Museo Canario de Las Palmas de Gran Canaria ${ }^{16}$, a las que ya poseía como resultado de los legajos consultados en el Archivo Histórico Nacional o de la exploración del catálogo de Gray Birch, etc. ${ }^{17}$

La tabla de causas de fe por Mahometanismo refleja unos vacíos y unos picos, que no sólo están en función de la especificidad del problema morisco en Canarias, sino también en relación con la evolución del propio tribunal inquisitorial canario.

En la tabla citacia, detectamos dos cuestiones singulares:

a) En el período 1521-35 aparece un acusado aumento, el cual resalta ostensiblemente al lado de los "vacíos" anterior y posterior.

b) A partir de 1556, y aun existiendo ciertas «ondulaciones», constatamos una continuidad en la acción de la Inquisición canaria.

${ }^{16}$ Aurina Rodríguez: «El Museo Canario. Catálogo y extractos de la Inquisición de Canarias», en Revista del Museo Canario 1966-69, pp. 129-143; 1970-71, pp. 135-168; 1975, pp. 141-157. Legajos MC CLXIX-24, CXVII-21, XXVI-24, LXXX-2, CXVIII-17, CXVIII7, LV-21, VII-9, CIV-14, XCVI-11, CXXIX-2, CXLV-23, CXXXI-17, XIII-44, CXII-13, LXI-7, CXLVIII-8, CLXXVIII-63.

17 Legajos A.H.N. 1829, $1831,1821,4520$.

Gray W. BIRCH: Catalogue of a collection of original manuscripts of the Inquisition in the Canary lslands, Londres 1903.

A. Millares ToRRES: Historia General..., op. cit.

-: Historia de la Inquisición en las Islas Canarias, Santa Cruz de Tenerife y Las Palmas de Gran Canaria 1981.

A. Rumeu de ARmas: Piraterias..., op. cit. 
Los quinquenios 1521-1525 y 1526-1530 almacenan la severa y sostenida labor desarrollada por el activísimo Inquisidor Martín Ximénez. En cuanto a la continuidad en el elevado número de causas de fe que observamos a partir de 1556, podemos ponerlas en conexión con varios fenómenos, unos internos y otros externos:

1. La mejor organización interna del tribunal canario. Hay a partir de 1567 un considerable aumento de personal especializado: alguaciles, visitadores, contador, fiscal, etc. ${ }^{18}$

2. La mayor frecuencia de viajes a Berbería para realizar rescates. Este fenómeno lo estudiaremos detenidamente en el próximo apartado.

3. La inequívoca posición de España como defensora de la unidad en la fe católica, sobre todo tras el viraje político de Felipe II en 1558.

4. La creciente importancia del tráfico marítimo, que hará pasar por Canarias multitud de barcos holandeses, ingleses y de otras nacionalidades, bien vinculados al comercio con América, o bien ligados a simple actividad pirática.

5. El notable incremento del celo religioso, fenómeno éste que ha de verse como una lógica consecuencia de las conclusiones alcanzadas en el Concilio de Trento (recordemos que finaliza en 1563). Estamos inmersos en una época clave para la historia de la Iglesia: la Contrarreforma.

6. La sensación de miedo dentro de la Cristiandad por la fulgurante expansión del Imperio Otomano. Esto hará que España participe muy activamente en la lucha contra la expansión musulmana. La Guerra de las Alpujarras en 1568-70 y la batalla de Lepanto en 1571 pueden considerarse dos importantes hitos en esta lucha. Por lo que respecta a Canarias, y en relación con la actividad del tribunal inquisitorial, el fenómeno citado adquiere tintes peculiarísimos: «huidas» $y$ «rescates».

${ }^{18}$ A. Millares Torres: Historia de la inq..., op. cit., t. IV, p. 154. 
La penuria de causas detectadas antes de 1523, puede atribuirse a varias razones:

a) El escaso poblamiento del archipiélago canario, recién salido de un largo período de enfrentamientos, período que finaliza con el triunfo del Adelantado Fernández de Lugo en la última isla sometida, Tenerife, en 1496.

b) La falta de una infraestructura social a todos los niveles (urbano, administrativo, de comunicaciones, etc.) y ello sobre todo en las tres islas mayores (Tenerife, Gran Canaria y La Palma), durante los primeros años del siglo XVI.

c) Dada la lejanía en el tiempo, y dada la incipiente creación del tribunal inquisitorial a nivel nacional en estos momentos a que nos referimos, así como una aún defectuosa ligazón administrativa del tribunal inquisitorial canario con sus órganos centrales peninsulares, cabe especular con que se haya producido una cierta desaparición de documentos correspondientes a estas fechas.

d) Hasta 1522 no se detectan cabalgadas a Berbería con una frecuencia realmente apreciable ${ }^{19}$.

En el corto período del inquisidor Martín Ximénez (1524-1527), prácticamente toda la gama de actos heréticos fueron perseguidos. Las causas de fe por Mahometanismo y por Judaísmo aumentaron espectacularmente. En el auto de fe de $1526^{20}$ aparece el primer contingente relativamente alto de moriscos. Son cinco los esclavos moriscos que desfilan en la ceremonia. Se trataba de beduinos mahometanos, los cuales, tras su captura en el continente africano, habían sido obligados a convertirse a la fe católica. Sin un convencimiento pleno en su nueva fe, habían sido sorprendidos en prácticas clandestinas de su antiguo credo religioso. Van en el auto con hábito de reconciliados, o sea con sambenito y coraza.

${ }^{19}$ M. Lobo Cabrera: La esclavitud..., op. cit., pp. 66-67 y 145-146.
20 A. Milares TORRES: Historia de la Inq..., op. cit., t. I, pp. 87-94. 
Tras una cierta atonía, las causas de fe debidas a Mahometanismo tiene un rebrote sorprendente en los primeros años correspondientes al mandato de $\mathrm{D}$. Luis de Padilla. Veinticuatro esclavos moriscos, la mayoría procedentes de la isla de Lanzarote, son reconciliados en Las Palmas durante el auto de fe de 1534.

Entre 1536 y 1548 hay un vacío notable. Ni en el catálogo de W. Gray Birch, ni en los legajos del Archivo Histórico Nacional, ni en textos tradicionales (Millares, Rumeu, Kamen, etc.) aparecen causas de fe correspondientes a esta fase. En mi reciente visita al Archivo del Museo Canario en Las Palmas, descubro que este vacío no es absoluto, aunque desde luego sí bastante grande, pues sólo aparecen unas 15 causas de fe para ese largo período, de las cuales escasamente tres son por Mahometanismo.

En relación con este curioso fenómeno, yo sostengo que fueron dos situaciones consecutivas, ambas relacionadas con problemas específicos de la Iglesia como organización, las que generaron esa penuria procesal.

En primer lugar hay que citar las irregularidades que acontecen en la Diócesis de Canarias tras el fallecimiento del obispo D. Juan de Salamanca, el 12 de mayo de 1534. Transcurren seis años hasta la toma de posesión del siguiente obispo, cargo que recaerá en fray Alonso Ruiz de Virués (monje benedictino propuesto por el emperador al papa Paulo III y autorizado por éste). Durante estos seis años, las pugnas entre el $\mathrm{Ca}-$ bildo catedralicio y la Inquisición fueron frecuentes ${ }^{21}$. Ello debió obstaculizar enormemente la labor del tribunal. El nuevo obispo, Virués, tuvo un corto mandato, pues falleció en Telde el 19 de enero de 1545. Ruiz de Virués era un prestigioso humanista, muy posiblemente vinculado a los círculos erasmistas. Estos círculos sabemos que estuvieron auspiciados por grandes políticos y literatos, entre otros los hermanos Valdés, muy queridos por el emperador. Este semblante de humanista, así como el hecho de haber sido procesado por la Inquisición sevillana, nos definen la segunda posible causa de este vacío de causas de fe.

Hasta el auto de fe de 1557 , no vemos un contingente grande de acusados por Mahometanismo de nuevo. Pero en la medida que se trata, en su mayoría, de relajaciones en estatua, los estudiaremos detenida-

21 -: Historia general.., op. cit., t. III, pp. 115-117. 
mente en el próximo apartado. Citemos, no obstante, el caso de Miguel González como un ejemplo curioso, dentro del auto de fe aludido ${ }^{22}$. Se trata de un «cristiano nuevo de moro", el cual se había convertido al Calvinismo. Pone de manifiesto el temprano cosmopolitanismo de Canarias. El tráfico mercantil anglo-holandés por la zona, se entrecruza con el comercio de esclavos moriscos. Muchos mercaderes y marinos norteuropeos hubieron de padecer también los rigores inquisitoriales. En las cárceles del Santo Oficio convivirían con esclavos moriscos. Curioso cruce de culturas, producido gracias a los "desvelos" del tribunal inquisitorial.

Durante el quinquenio 1566-70, detectamos una espectacular aumento de causas de fe. Es un momento éste en el que el inquisidor D. Luis de Padilla, muy envejecido, será sustituido por Ortiz de Fúnez ${ }^{23}$. El licenciado D. Diego Ortiz de Fúnez había ejercido ya como fiscal de la Inquisición foledana. Llega a Canarias con una aureola de hombre enérgico y de buen organizador. Su efectividad fue notable, pues el seis de noviembre de 1569 , organiza ya su primer auto de fe.

Permanece Ortiz de Fúnez catorce años como inquisidor de Canarias, sucediéndole en 1581 los inquisidores Diego Osorio de Seijas y Juan Lorenzo. Durante el período del inquisidor Ortiz de Fúnez, tienen lugar cuatro autos de fe, tres de ellos con una muy nutrida comitiva de herejes penitenciados. Dada la vigencia del acuerdo hispanobritánico, conocido en la historiografía como el acuerdo Alba-Cobham, las causas de fe por Protestantismo no van a abundar. En cuanto a judeoconversos, tras la dura represión a la que ya habían sido sometidos, no parece que osasen acercarse por el archipiélago. Las miras de los inquisidores se dirigen ahora, fundamentalmente a moriscos esclavos, que convertidos a la fe católica, persisten aún en sus ritos mahometanos a escondidas.

Observando la tabla I, sorprende el número tan elevado de delaciones para el período que va de 1568 a 1572. Pero no nos debe pasar desapercibido que en 1570 llega a Las Palmas un visitador general que enviaba la Suprema. Se trataba del doctor Bravo de Zayas. Este activísimo inquisidor-inspector gira una visita ${ }^{24}$ por todo el archipiélago, comenzando su periplo en la isla de Tenerife en agosto de 1571. Durante

\footnotetext{
22 A.H.N. legajo 1829.

23 Real Cédula expedida en Madrid el 10-octubre-1567.

24 A. Millares Torres: Historia general..., op. cit., t. III, pp. 205-206.
} 
esta visita, cosechó un enorme conjunto de delaciones, que explican la aparatosa cifra que Gray Birch nos brinda en su catálogo para el citado período 1568-1572.

Entre 1571 y 1591, las causas de fe por Mahometanismo siguen siendo frecuentes. Las tres causas que explican esta continuidad son: la llegada de esclavos moriscos, que aunque menor, continúa, sus intentos de huida y los rescates en Berbería. El espectacular aumento de los rescates explica que sea el delito "por intentar ir a Berbería a tornarse moros» prácticamente el único a partir de este momento.

\section{LA ABUNDANCIA DE LAS QUEMAS EN EFIGIE}

Vamos a tratar de encontrar, si es que la hubo, una relación entre el fenómeno esclavista y la acción inquisitorial. Ya hemos entrevisto una cierta relación muy elemental, pues la población morisca del archipiélago era, prácticamente toda ella, población esclava. Ahora bien, lo que más nos interesa, es establecer una correlación estadística, más o menos precisa, si es que la hubiere. Y para ello, nos vamos a ayudar de las extraordinarias tablas y no menos estupendos gráficos, que Lobo ${ }^{25}$, en su libro sobre esclavitud, pone a nuestra disposición. Intentaré establecer una relación entre sus estudios estadísticos (expediciones y cabalgadas, compradores de esclavos, esclavos por raza y fecha) y mis gráficos y tablas. Quizás esta comparación pueda darnos respuesta a diversas cuestiones:

1. ¿En qué grado obstaculizó la Inquisición este mercado esclavista con sus persecuciones, condenas y controles?

2. ¿En qué medida cabe hablar de una resistencia por parte de los moriscos a acatar realmente la fe católica? ¿Y en qué medida esta resistencia pudo forzar a que el mercado esclavista se

M. Lobo Cabrera: La esclavitud en las Canarias Orientales en el siglo XVI (negros, moros y moriscos), Las Palmas, 1982. 
orientara hacia el Africa Negra cada vez más, tal y como Manuel Lobo lo pone de manifiesto en sus estadísticas?

3. ¿Es posible encontrar una correlacción entre los rescates y la «huidas» a que alude la Inquisición, huidas que propiciaban las condenas de quema en efigie en los autos de fe?

4. ¿Qué correspondencia cabe encontrar entre las comparecencias de esclavos en mercado y el número de causas de fe para cada período correspondiente?

Analicemos de nuevo la distribución de causas de fe por Mahometanismo expuesta en el gráfico II que mostramos al final del trabajo. Esta distribución nos muestra tres claros picos (1526-35, 1556-60 y 1571-89) $y$ tres claros vacíos (1493-1526, 1536-46, 1561-71). Ahora calculemos cuántos reos fueron quemados en efigie, y cuántos penitenciados directamente de uno u otro modo. Señalemos como dato curioso la inexistencia de relajaciones en persona para este tipo de causas de fe. Ello parece mostrar una relativa benignidad de la Inquisición para con los moriscos, lo que pone de manifiesto que muy posiblemente el tribunal inquisitorial no desease interferir de manera negativa en el mercado esclavista. Asimismo, dada la poca infuencia social de los esclavos moriscos, es también posible que los inquisidores no contemplararan la eventualidad de una peligrosa expansión de la fe islámica por el archipiélago.

En la tabla VI se muestra la distribución de condenas mencionada. De las 200 causas de fe que por Mahometanismo tengo catalogadas para el siglo XVı en Canarias, cerca de la mitad (97), acaban en quema de efigie. Tal cifra es forzosamerite significativa. Sin desdeñar que algunas de las muchas huidas a que alude la Inquisición pudieran haber sido ciertas, se nos antoja que en la mayoría de los casos se trata más de rescates que de huidas. Antes de intentar demostrar esta suposición, parece necesario definir una serie de conceptos fundamentales.

En primer lugar, indiquemos que la condena a ser relajado en estatua tenía lugar cuando el encausado se hallaba huido (vivo o muerto). Por tanto, en los 97 casos a que aludimos, los reos, que en su inmensa mayoría eran esclavos moriscos, ya habían retornado a su tierra (Berbería) con los suyos, cuando el Santo Oficio dictaba contra ellos sentencia en el archipiélago canario. O bien habían perecido ahogados al tratar de 
escapar navegando desde las islas en dirección a tierra continental africana.

En segundo lugar, se hace necesario que definamos el término "rescate». Y más que específicamente definirlo, pasaré a comentar un poco en detalle este interesante fenómeno, del cual Lobo nos habla extensamente en el estudio citado ${ }^{26}$. Entre 1519 y 1572 parten abundantes expediciones, llamadas "cabalgadas", que desde Canarias van a penetrar en tierras de Berberia. Su frecuencia media era de dos a seis por año. Pasado el año de 1572, decrece esta frecuencia, debido a la prohibición promulgada por Felipe $1{ }^{27}$. Sin embargo, a pesar de esta prohibición, continúan realizándose entradas de tipo pacífico, entradas que con anterioridad a esta fecha ya existían simultánemante con las cabalgadas. Son los llamados "rescates", en los que se realizaba un trueque de moros, los cuales habian sido apresados en cabalgadas anteriores, por cristianos que habían caído en manos moras, o por esclavos negros, o bien, en última instancia, por cueros, ganado $u$ otros bienes materiales.

En los llamados «rescates de moros», los más frecuentes, se fletaban navios de una forma muy similar a cuando se organizaban asaltos armados. Se adentraban los traficantes tierra adentro en Berbería, acompañados de adalides, los cuales concertaban las condiciones del cambio. Los navíos quedaban a la espera fondeados cerca de la costa. $Y$ frecuentemente ocurría que su tripulación saqueaba lugares cercanos, hacía pesquería o recogia orchilla. El cambio que los dueños solían pedir era de dos o más esclavos negros jóvenes (de 18 a 20 años) por el morisco que ellos devolvian. No importaba que los esclavos negros fuesen varones o hembras. Interesaba, eso sí, que estuviesen sanos y fuertes. Gran parte de estos esclavos acababan siendo destinados a plantaciones, sobre todo ingenios azucareros.

En cuanto a los "rescates de cristianos", la mecánica era similar, sólo que ahora no existía una intencionalidad fundamentalmente económica, sino humana. La cautividad de cristianos en territorio moro, así como su forma de rescate, era bastante conocida entre los castellanos. Ello aparece además legislado en las Ordenanzas Reales de Castilla,

${ }^{26}$ Ibidem, págs. 90-97.

${ }_{27}$ Ibidem, págs. 56. LoBo alude aquí a un documento sito en el archivo municipal de La Laguna ( $R$ VIII $\left.n .{ }^{\circ} 45\right)$. La prohibición de Felipe ll se debe a las incursiones que los corsarios berberiscos hacian sobre las islas. 
publicadas en Salamanca en 1560. Varias causas explican la presencia de cautivos canarios cristianos en tierras de Berbería: unos habían sido traicionados por sus adalides en alguna entrada, otros sencillamente apresados en alguna cabalgada, pesquería o rescate frustrado.

Hasta el auto de fe de 1526 no vemos comparecer ante el Santo Oficio ningún esclavo morisco, aunque sí vecinos moriscos en muy exigua cantidad. Hasta el auto de fe de 1530 no hay quemas de estatuas. Veamos qué razones pueden explicar esta carencia:

1. La inicial dedicación del tribunal de la Inquisición a la persecución de los casos de Judaísmo por encima de cualesquiera otros.

2. La escasez de esclavos moriscos en el mercado canario durante los primeros años del siglo XVI. Entre 1510 y 1521 sólo constan 27 esclavos compareciendo en mercado, de los cuales 16 son negros ${ }^{28}$.

3. El que hasta 1530 no hubieran quemas de estatuas se debe también a que, al haber pocos esclavos moriscos en las islas aún, tampoco resultaba factible la existencia de rescates, ni frecuente la eventualidad de las huidas.

Entre 1522 y 1524 comparecen un total de 83 esclavos en el mercado esclavista canario. Esto se corresponde muy bien con el "pico" de mis tablas entre las fechas de 1526 y 1535 (45 causas de fe hay para este intervalo). Teniendo en cuenta el hecho de que siempre puede producirse un cierto desfase cronológico entre la aparición en las islas de dichos esclavos y las aperturas de procesos a los mismos con sus ulteriores condenas, la correspondencia citada parece razonable.

En el auto de fe de 1530 tiene lugar la primera quema de estatuas. Son seis en total y corresponden a seis esclavos moriscos: Francisco y Alonso, esclavos de Alonso Pérez; Francisco, esclavo del licenciado Francisco Pérez de Espinosa; Fernando, esclavo de Pedro Gómez Tamborino;

${ }^{28}$ Ibidem, p. 145. 
Andrés, esclavo de Mari Calva; y Manuel, esclavo de Cubas, alguacil de Telde. Tiene lugar esta condena, según nos cuenta Millares ${ }^{29}$, por haber estos esclavos robado una barca en el Puerto de las Isletas, con la que pretendían huir a su tierra. Pero todos perecieron ahogados.

La tendencia a la huida debe pensarse como lógica en un esclavo, pero el marco geográfico que para tal decisión se le ofrece en el archipiélago canario, no resulta muy propicio. Veremos más adelante, que si bien ciertamente algunas huidas sí se produjeron, cabe sospechar que otras fueron realmente rescates.

En el auto de fe de 1534 son reconciliados 24 esclavos entre moros, negros e indios. Indio en realidad sólo desfila uno, negros comparecen cuatro. La denominación indio se utiliza en la época, tanto para nombrar a los asiáticos de la India portuguesa, como a los americanos procedentes de las «Indias" españolas o de Brasil. El primer indio que comparece en el mercado esclavista canario, lo hace en $1537^{30}$, pero se sabe que con anterioridad ya había indios en el archipiélago canario. En el año 1506 hay datos de que en Tenerife una india es vendida a un genovés, $y$ en 1514 se hace escritura por la venta de otro indio ${ }^{31}$. En general son pocos los indios de los que se tiene referencia. Comparecen como esclavos un total de 15 a lo largo de todo el siglo XVı en el mercado de esclavos de Las Palmas. $Y$ condenados por la Inquisición, únicamente detectamos este caso de 1534.

Los negros sí son abundantes, bastante más incluso que los moriscos. A partir de 1530, y ya ininterrumpidamente hasta finales del siglo $\mathrm{XVI}$, forman el 70 por 100 , o más del total de la población esclava de las islas ${ }^{32}$. Sin embargo, la Inquisición no procesa a muchos, si comparamos con el elevado número de moriscos reconciliados o quemados en estatua.

El esclavo negro se comportaba de un modo mucho más sumiso. Profesaba generalmente unas creencias religiosas más primitivas, menos sofisticadas, menos dogmáticas. Aceptaba sin rebeldía la nueva fe, la fe

zo A. Millares Torres: Historia de la Inquisición..., t. I, p. 98 . Millares extrae su información del libro $1 .^{\circ}$ de Quemados, hoy en el Museo Canario de Las Palmas.

${ }^{30}$ M. Lobo CaBaera: La esclavitud..., op. cit., p. 155.

${ }^{31}$ Ibidem, p. 155. Extrae Lobo esta información de M. Marrero Rodriguez: «De la esclavitud en Tenerife", Revista de Historia, n. ${ }^{\circ} 100$, La Laguna 195, pp. 428-441.

32 Ibidem, gráfico de la p. 149. 
católica que le era impuesta, o en su caso la que sus compañeros moriscos le inculcaban, o sea la fe islámica. En su mayoría se plegaron sin problemas a la religión de sus amos, siendo más bien excepción los convertidos al Mahometanismo.

En los escritos de la época, inquisitoriales, notariales u otros, aparecen diversas denominaciones para designar a los esclavos procedentes de Berbería. El término moro era el más general, y englobaba a las otras tres denominaciones usuales: moriscos, blancos y berberiscos.

Hasta el auto de fe de 1557 no hay más quemas en efigie. A lo largo de un período tan dilatado, escasean las causas de fe de cualquier tipo. Veamos si, además de las razones apuntadas en el apartado anterior, podemos detectar un hipotético bajón en las cabalgadas a Berbería.

A partir de 1535 y hasta 1552, no comparecen muchos esclavos en mercado (una media de ocho esclavos/año) ${ }^{33}$. Las cabalgadas y expediciones desde Gran Canarias, Fuerteventura y Lanzarote escasean: únicamente siete a Berbería y una a Cabo Verde ${ }^{34}$. Esta atonía, tanto en la actividad inquisitorial, como en las cabalgadas en busca de esclavos, explican el "vacío» de la tabla III. No obstante, aparecen algunos casos aislados dignos de comentarse. En el auto de fe de 1548 desfila como penitente Diego Domínguez por «falsario» ${ }^{35}$. La condena que se le impone es de ser «penitenciado y traído a la vergüenza pública por las calles sobre un asno y desterrado a las galeras de su majestad", ello por haber vendido a un muchacho cristiano a los moros haciéndole pasar por moro y llamándolo Almanzor, dejándole al final en poder de aquéllos. La Inquisición hace un especial hincapié en el hecho de "haberlo hecho pasar por moro", pues en otro caso el tema ya no hubiera sido incumbencia de la justicia inquisitorial. Digamos además, a modo de curiosidad, que esta causa de fe viene en un documento manuscrito, el más antiguo de los legajos que yo hasta la fecha he podido consultar en relación con entradas a Berbería citadas por la Inquisición.

Los moriscos, generalmente, poseían unas creencias religiosas muy sólidas. Aun cuando fueran obligados a bautizarse y convertirse a la fe católica, muchos de ellos seguian firmes en sus ideas islámicas. Resulta

${ }^{33}$ Ibidem, cuadro de la p. 145.

${ }^{34}$ Ibidem, cuadros correspondientes a las pp. 66, 67, 68, 107 y 114.

${ }^{35}$ A.H.N., Inquisición, legajo 1829, «causas correspondientes al auto de fe de 1548». 
sintomático el caso de Sancho de Arzeo, morisco penitenciado en el auto de fe de $1548^{36}$, el cual desfila con una mordaza en la lengua, por decir «pese a Dios y descreo de Dios y soy de Berbería y si estuviera cerca me tornaría moro y reniego del bautismo...»

A partir de 1552 y hasta fin de siglo, asistimos a una continuada y gran comparecencia de esclavos en el mercado. Aparecen algunos bajones, como por ejemplo en 1566 y 1587, pero también algunos picos espectaculares, como los 61 de 1562, los 48 de 1574 o los 53 de $1582{ }^{37}$. Este incremento inicial y posterior continuidad en la venta de esclavos procedentes del continente africano, se corresponde con la acción inquisitorial coetánea. A partir del auto de fe de 1557, en el que se queman 17 estatuas correspondientes a 16 moriscos y un guanche huidos, no hay ya auto de fe (a excepción tan sólo del de 1597) en el que no se quemen estatuas por Mahometanismo.

Los autos de fe se suceden ahora con una gran regularidad. Entre 1561 y 1570 no obstante, hay un fuerte bajón en la persecución inquisitorial contra los moriscos. ¿Por qué? Las cabalgadas no se interrumpen, pero curiosamente sí observamos una menor frecuencia de las mismas en el período que comentamos. Entre 1552 y 1560 hay un total de 21 cabalgadas a Berbería, pero entre 1561 y 1570 sólo son cinco las cabalgadas que pueden contabilizarse ${ }^{38}$. Sin embargo, con las expediciones al Africa Negra ocurre lo inverso. Así, vemos cómo entre 1552 y 1560 sólo constan dos de estas expediciones, mientras entre 1561 y 1570 aparecen $10^{39}$.

El fenómeno comentado de alternancia entre cabalgadas y expediciones, explica satisfactoriamente el sostenimiento del número total de esclavos en venta, y también el bajón en la acción inquisitorial, pues el esclavo negro, como ya se ha comentado, apostataba con mucha menor frecuencia de la fe católica que se le imponía.

Dentro de la información correspondiente al auto de fe de 1574, tenemos ya constancia escrita sobre existencia de rescates en los legajos inquisitoriales. Resulta esto lógico si recordamos la ya citada prohibición

\footnotetext{
${ }^{36}$ A.H.N., Inquisición,m legajo 1829 , ibidem.

37 M. LoBo CABRERA, op. cit., pp. 145 y 146.

$38 \mathrm{Ibidem}$, Cuadros correspondientes a las pp. 66, 67 y 68 .

39 Ibidem, Cuadros correspondientes a las pp. 107, 114.
} 
de Felipe II sobre cabalgadas armadas a Berbería, prohibición promulgada en 1572. Este decreto condujo a un aumento de las entradas pacíficas. En la "Carta al Consejo" donde se alude al citado auto de fe, se nos dice, en relación con 15 esclavos acusados todos ellos de «apostasía»:

«En el año de 1563, 15 esclavos, todos cristianos que estaban con sus amos en la isla de Tenerife, se concertaron en tomar un barco y pasarse a Berbería, y así lo hicieron, y estando allá, ocho de ellos se tornaron moros y se quedaron allí y los otros siete fueron capturados y los trocaron y dieron por rescate de otros moros que estaban en estas islas de Lanzarote y Fuerteventura. Uno de estos siete logró escapar. Contra los otros se ha procedido al Santo Oficio. Se llamaban Ala, Esteban, Augustín, Domingo, Simón y Domingo, todos negros...» ${ }^{40}$.

Lo que más sorprende en esta información es que hayan logrado realizar tan larga travesía sin incidencias. Los esclavos, tanto moriscos como negros, solían ser legos en las artes de la navegación. Por otra parte, la mar que rodea al archipiélago canario es pródiga en turbulencias. No ofrecen estos mares los riesgos de una galerna en el Cantábrico o un tifón en el Caribe, pero la mar gruesa se presenta con suma frecuencia y los temporales abundan. En pequeñas embarcaciones a vela, y $\sin$ experiencia marinera, la llegada al continente africano desde las islas más occidentales resulta poco menos que imposible.

Podemos muy fundadamente sospechar, que la explicación dada por el Santo Oficio, a que antes hemos aludido, haya sido más bien un informe de conveniencia dado por los mercaderes de esclavos al tribunal inquisitorial, a fin de no tener que cumplir las severas pragmáticas de aquél. Estas pragmáticas salen a la luz en 1566 y obligan a que ningún morisco pase a Berbería sin licencia, así como a que los barcos canarios vayan a Las Palmas antes de salir en dirección al continente africano a efectuar rescate. Se aduce que debe interrogarse a los moriscos y conocer sus creencias religiosas ${ }^{41}$. Las órdenes del Santo Oficio citadas, provoca en 1567 una seria protesta de uno de los organizadores más potentes: Don Agustín de Herrera y Rojas, conde y marqués de

\footnotetext{
${ }^{40}$ A.H.N., Inquisición, legajo 1829, "causas correspondientes al auto de fe de 1574».

${ }^{41}$ M. LoboCabrera: La esclavitud..., op. cit., p. 92.
} 
Lanzarote ${ }^{42}$. De este interesante manuscrito presento la transcripción íntegra en el próximo apartado.

Intentos de huida frustrados si se detectan muchos. Así, el 17 de marzo de 1573 se inicia una causa de fe contra siete esclavos negros y moros que ensayan una fuga a Berbería desde la isla de Canaria (actual Gran Canaria), pero que acaban siendo descubiertos y apresados ${ }^{43}$. En el legajo consultado por mí, no consta qué condena se les llegó a imponer.

Otro intento de huida, también finalizado con el apresamiento de los esclavos fugitivos, es aquel que acaba con los reos encausados desfilando en el auto de fe de 12 de diciembre de 1574. En este proceso, los inquisidores amenazan con el tormento a uno de los acusados, fenómeno éste bastante extraño en las causas de fe por Mahometanismo, por lo menos en el ámbito canario. Veamos lo que nos dice en concreto el manuscrito sobre este caso:

«Francisco, Salvador, Luis y loan, esclavos en isla de Tenerife, se concertaron de tomar un barco e irse a Berbería a tornarse moros. Por haber mal tiempo, hubieron de volverse. El dicho Francisco confesó, tras habérsele notificado la sentencia de tormento. Fue admitido a reconciliación y a salir al auto de la fe en forma de penitente con su hábito, y a confiscación de bienes, y a estar recluso en un monasterio por un mes para ser instruido en la fe católica a costa de su amo... " ${ }^{44}$.

El tormento, como hemos visto en el párrafo anterior, llegó a ser profusamente utilizado en los tribunales inquisitoriales españoles, sobre todo en los casos de Judaísmo y Protestantismo, pero en los casos de Mahometanismo no pasaban de ser puras amenazas, salvo alguna excepción. Tal sucedió con el reo Pedro Manio, morisco esclavo de Hernandianes, vecino de la isla de Tenerife, condenado en el auto de fe de 24 de junio de 1576 por «intenciones sospechosas de Mahometanismo" ${ }^{45}$. Se le sometió a tormento para que revelase cuál era su intención al querer ir a Berbería, y "negó que se quisiese convertir a la

\footnotetext{
${ }^{42}$ A.H.N., Inquisición, legajo 4520 n. ${ }^{\circ} 6$.

${ }^{43}$ A.H.N., Inquisición, legajo 1821.

44 A.H.N., Inquisición, legajo 1829, "causas correspondientes al auto de fe de 1574".

45 A.H.N., Inquisición, legajo 1829, "causas correspondientes al auto de te de 1576".
} 
religión morisca, aunque sí dijo que quería fugarse a Berbería.» Fue condenado a salir al auto en forma de penitente, a abjurar de vehementí, a que le fuesen dados doscientos azotes, y a ser devuelto a su amo.

En cuanto al número de estatuas quemadas, sobresalen las del auto de 1581 . Se refieren a 31 «fugados" desde Lanzarote, dirigidos por el rico comerciante Felipe ${ }^{46}$. El proceso de fe contra este rico morisco avecindado en la isla de Lanzarote, así como contra Hernando Felipe, se inicia en Las Palmas el 13 de noviembre de $1554^{47}$. Según Millares ${ }^{48}$, este Juan Felipe, «temiendo ser algún día perseguido por su propia fe, fletó un buque con el pretexto de ir a Tenerife, y se embarcó con su mujer, hijos, familia y unas treinta personas más...". En el auto de fe de 6 de noviembre y siempre siguiendo a Millares, es quemado en estatua junto a las efigies de Benito Herrera y Hernando Felipe, moriscos también. Lo curioso es que en el auto de fe de 12 de marzo de 1581, de nuevo se quema la estatua de Juan Felipe así nos lo recalca Millares, junto con las de los 30 restantes reos fugados. ¿Por qué no se hizo la quema de las 30 estatuas ya en el auto de fe de 1569? ¿Por qué se quema la estatua de Juan Felipe en dos ocasiones? La verdad es que Millares no especifica de dónde saca todos estos datos cuando habla del auto de fe de 1569. Con referencia a las tres estatuas sí cita el origen de la información ${ }^{49}$, pero con referencia a los otros aspectos sólo dice: "así resulta de su proceso». Consultando detalladamente las "Cartas al Consejo" dentro de los legajos del Archivo Histórico Nacional, y concretamente el 1829, compruebo que en el auto de 1581, si bien se cita en diversas ocasiones el nombre del morisco Juan Felipe, no consta de manera explícita que haya sido quemada su efigie. De quienes sí constan las efigies son de su hijo y de su nieto.

Sin querer apuntar nada seguro, pues quedan muchos casos por investigar concienzudamente, podemos aventurar que debía existir una pugna muy dura entre el tribunal de la Inquisición, deseoso de salvar almas y extirpar la herejía, y los mercaderes de esclavos, deseosos de incrementar sus beneficios. Las quemas en efigie pueden interpretarse como advertencia ante las sucesivas "huidas" de almas ya convertidas

${ }^{46}$ A.H.N., Inquisición, legajo 1829, «causas correspondientes al auto de fe de $1581 »$ y A. Millares Torres: $H .^{a}$ de la Inq..., $\mathrm{t}$ II, p. 26, p. 72.

${ }^{47}$ W. Gray BIRCH: op. cit., fol. 309.

${ }^{48}$ A. Millares Torres: $H^{a}$ de la inq., op. cit., t. II, p. 72.

${ }^{49}$ Ibidem, Millares cita el libro 2. ${ }^{\circ}$ de Quemados, fol. 263. 
a la fe católica. No obstante, cabe pensar en que el Santo Oficio se consolase con el razonamiento de que a cambio de cada alma morisca perdida venían dos de negros.

Cerraré este apartado con un curioso caso correspondiente al auto de fe de 22 de julio de 1587. En este caso queda claramente de manifiesto la relación existente entre los fenómenos «huida» y «rescate». La mujer encausada es una morisca de nombre Ynés de Vega, de 70 años de edad, natural del castillo de Arguin en Berbería, hija de padres moros y viuda de Jorge Ramírez, morisco, de profesión herrero, vecino de Canaria. Se la condena a salir al auto en forma de penitente, abjurar de Leví, permanecer reclusa tres meses en una casa honrada a fin de ser instruida, y pagar diez doblas para gastos del Santo Oficio. La causa de tal castigo era que «al ir como intérprete a Berbería para un rescate, quedó allí un tiempo huida y fue testificada de que alli decía que era mora y hacía vida de mora y comía carne los viernes... ${ }^{50}$.

\section{UN DOCUMENTO EXCEPCIONAL: LA PROTESTA DE AGUSTIN DE HERRERA}

Este documento ${ }^{51}$ consta de dos partes. La primera - primeras dos láminas-, es el poder que Agustín de Herrera y Saavedra, señor de las islas de Lanzarote y Fuerteventura, otorga a Luis de Orive, Gaspar de la Cerna y Juan López, para que le representen. La segunda, - siguientes dos láminas-, expone la protesta de D. Agustín de Herrera contra la orden de la Inquisición de que ningún navío pueda ir de esas islas a rescatar a Berbería sin que antes vaya a la isla de Canaria a hacer registro en el Santo Oficio. Fecha: 1567.

Dentro de la primera parte, la que compone el poder otorgado por Agustín de Herrera, destaquemos aquel fragmento del relato en el que el propio Herrera, a fin de persuadir a los inquisidores, justifica los rescates, no sólo porque «rredunda mucho Servicio a Dios Nuestro Señor» y "suelo hacer al servicio de sus magestades", sino porque "vienen a

\footnotetext{
${ }^{50}$ A.H.N., Inquisición, legajo 1829, "causas correspondientes al auto de 1587 ".

51 A.H.N., Inquisición, legajo $4520, n .{ }^{\circ} 6$.
} 
tierra de cristianos muchos negros los quales se tornan cristianos". Este trueque de un moro que vuelve a su tierra por varios negros, que los moros dan a cambio, es un suculento negocio para los mercaderes de esclavos de las islas. La Inquisición no puede tolerar que «huyan» almas convertidas, y los mercaderes no están dispuestos a dejar escapar los grandes beneficios de tan singular comercio. Todo ello justifica que en los autos de fe aparezcan tantas quemas de efigie, como ya vimos en el apartado anterior.

En la segunda parte, el apoderado Luis de Orive expone nítidamente ya los objetivos de los tales rescates: "dan por si dos o tres o quatro o mas piezas de negros que traydos a las islas se tornan cristianos...» Siempre, por supuesto, el argumento religioso como telón de fondo. Para no tener que ir a la isla de Canaria a correr el riesgo de poder perder un buen negocio, se arguye que «ir de Lanzarote a Canaria hay mucho camino y mucho riesgo y peligro de corsarios y enemigos luteranos». $Y$ se ofrece una alternativa: «esto también lo puede hazer el vicario de qualquiera isla que tiene a su cargo las ánimas de los fieles cristianos". Al margen de que los riesgos de la travesía pudieran ser más o menos ciertos, es obvio que siempre sería mucho más fácil la negociación con un vicario permanente en la propia isla que con un Consejo inquisitorial, mucho más severo e inflexible.

En realidad, la intencionalidad religiosa de Agustín de Herrera, no era más que una excusa. Cuando Felipe II, en el mismo año de 1567, elevó la casa señorial de Herrera a la dignidad de título de Castilla, esto no hizo más que envalentonar a Herrera, para que éste siguiese realizando, no sólo rescates, sino depredaciones brutales en Berbería ${ }^{52}$.

Transcripción:

(1. lámina)

Sepan quantos esta carta vieren como yo Agustín de Herrera Saa-

52 A. Rumeu de Armas: Piraterías..., op. cit., p. 479. 
vedra, señor destas islas de Lanzarote y Fuerteventura, otorgo y conosco que doy e otorgo todo mi poder cumplido libre e certero bastante según yo lo sé y tengo e según que mejor y más cumplidamente lo puedo e debo dar e otorgar e desto más e mejor puede e deve valer. A Luis de Oribe y a Gaspar de la Cerna y a Juan López rresidentes en Cortes de su magestad rreal y solisitadores en ella a todos tres juntamente e a cualquier dellos por si aya solo de un que son absentes como si fuesen presentes. Generalmente para en todos mis pleitos y causas y negocios movidos y por mover quantos yo tengo y espero tener contra qualesquiera personas o cualesquiera personas contra mí en cualquier manera. Para que ansi demandando como defendiendo puedan parescer e parescan ante sus cristianas e católicas magestades $e$ ante los señores del su muy alto Consejo presidente e oydores, alguaciles e notarios de su casa e Corte e chancillerías e ante estas qualesquier que las alli dichas dignidades eclesiásticas e seglares de cualquier fuero y jurisdicción que se anque de mis pleytos y causas puedan e devan librar e conoscer e ante ellos e cualquier dellos puedan demandar y defender y rresponder, negar y conoscer pleyto o pleytos contestar exebciones e difinsiones. E para jurar por mi ánima qualesquier juramento e juramentos así de calunia como desisorio e de verdad decir e pedir sean fechos por la otra parte o partes contrarias. E para que por mi y en mi nombre puedan todos los tres juntamente o cada uno e qualquier de ellos parescer e parescan ante el muy reverendísimo señor arzobispo de Sevilla e inquisidor general de los rreynos y señoríos de Castilla e ante el presidente del Consejo de la Santa Inquisición e ante los otros Señores de este Santo Concejo e ante ellos e ante qualesquier dellos pedirseme hagan e den licencia para que yo pueda enviar a rrescatar a Berbería algunos de los moros que yo en la dicha Berbería cada un año commo persona y vasallos tenga y que acostumbro tomar en las Armadas que ordinariamente suelo hacer al servicio de sus magestades contra moros de donde rredunda mucho Servicio a Dios Nuestro Señor e los dichos rrescates que yo hago por que por cada un moro de los que embio a rrescatar me dan diez y doze e quince e veynte y treinta y quarenta y cinquenta.

Transcripción:

(2. lámina):

negros según cada uno de los dichos moros tiene la hacienda y valor sin que por un solo moro que se rrescata vienen a tierra de cristianos muchos negros los quales se tornan cristianos y luego como se ven acá piden el santo babtismo y muchas veces por un miño fijo de qualquier moro rrico se traen diez y doze negros y se tornan luego cristianos como es muy cierto y notorio de lo qual Dios nuestro Señor se sirve asi 
aumentar su santa fee católica. $E$ doyles este dicho mi poder para que en dicho Consejo o en qualquier de los demás rreales consejos puedan sacar y pedir qualesquier escrituras e provisiones asi tocantes e pertenescientes a esta carta de poder de cualquier secretarios o escribanos e notarios que las tengan e para hacer cualesquier embargos e yncautaciones e prisiones e ventas y levantes de bienes e para poner artículos y posesiones e para presentar las cartas e instrumentos de toda esta manera de prueba e de presentar y jurar y conoscer los testigos de las otras partes e pedir publicación de testigos e abonar mis testigos e probanzas e tachar e contradecir los del contrario ansi en dichos como en personas e para ganar e ympetrar de sus magestades reales y de las dichas sus cuentas quales quier cartas y sobre cartas, cédulas y provisiones que a mi asi convengan y para concluyr e litigar rrazones e pedir sentencia e sentencias asy ynterlocutorias como definitibas e que las que en mi fabor sean consentir e de las de contrario apelar e suplicar e para hazer todas las otras cosas e deligencias e abtos judiciales y estrajudiciales que a la calidad de los dichos mis negocios convengan de se hazer e que yo mismo haría e hacer podria presente siendo aunque aquí no se declaren ni especifiquen para lo qual todo que dicho es así tener y guardar y cumplir e a quien firme obligo mi persona y bienes rrayces y muebles avidos e por a dicha fecha la carta en la villa de Teguise que es en esta ysla de Lanzarote en veynte y seys dias del mes de noviembre año del nascimiento de nuestro salbador lesu Cristo de mill e quinientos y sesentayseys que fueron presentes a los que a dicho es Francisco de Rriba alcalde mayor desta ysla e Andrés Rruyz e Gaspar estos alguaciles desta ysla y su señoría del dicho Agustín de Herrera mi señor lo firmo de su nombre aqui a quien yo el presente escribano doy fe que con nos y es el dicho en este poder yo Díaz de Moron escribano público.

(rúbrica de Agustín de Herrera)

Y yo Díaz de Morón escribano público desta ysla de Lanzarote por los muy ilustres señores della lo es asi i es aquí e corregir con el original según que ante mí paso y en fee y testimonio de verdad hize aquí mi signo.

(rúbrica de Díaz de Morón) 


\section{Transcripción:}

\section{(3. ${ }^{a}$ lámina):}

Luis de Orive. En nombre de Agustín de Herrera cuyas son las islas de Lanzarote y Fuerteventura. Digo que después que aquellas islas están en conoscimiento de nuestra santa fee catholica siempre los que han sido señores dellas han hecho guerra a moros por estar cerca de Berbería y han hecho sus Rescates de los mismos moros que han cauptivado sin que en ello se les aya puesto impedimento alguno. $Y$ de pocos años a esta parte por los ministros del Santo Oficio de la Inquisición de la isla de Canaria sea querido que ningún navío de las dichas islas de Lanzarote y Fuerteventura pueda ir a rescatar a Berbería sin que vaya primero a la isla de Canaria y alli haga registro en el Santo Oficio de todas las personas cristianos y moros que van al tal rescate. Lo cual es en muy gran daño del Sr. Agustín de Herrera y de sus islas. Porque el trato de la dicha guerra y rescate está muy cerca de las dichas islas a Bervería pues hay un día o noche de travesía de una parte a otra e ir de Lanzarote a Canaria hay mucho camino y mucho riesgo y peligro de corsarios y enemigos luteranos y de otras naciones que ocurren allí. Por ser el principal passo que Vuestra Alteza tiene para las Yndias y por yr de Lanzarote a Canaria los enemigos han tomado y robado mucho navios que ha sido muy gran desastre y vuestro. Lo otro se les haze muy grandes costos y gastos e ir de Lanzarote a Canaria que son mayores que la jornada de ida y vuelta a Bervería y en Canaria detienen los navíos y gente muchos días en que ha acaecido por los tiempos contrarios que han sucedido dexar de hazer el viaje y bolverse a Lanzarote sin aver fecho lo otro. Los moros que se ynbian a los tales rescates son personas de entendimiento y juicio y de libre alvedrío para escoger si quieren ser cristianos o no y determinados de bolverse a su secta mahometana pues no pueden ser fozados a nuestra religión se llevan al dicho rescate y dan por si dos o tres o quatro o mas piezas de negros que traydos a las islas se tornan cristianos y así se multiplica mucho mas en reduzir y traer a nuestra santa fee catholica muchas ánimas más por los rescates que si se dexasen de hazer. Lo otro se ha visto y entendido que el efecto para que se haze la dicha vissita a Canaria es para entender si los tales moros quieren ser cristianos y esto también lo puede hazer el vicario de qualquiera isla que tiene a su cargo las ánimas de los fieles cristianos o qualquier otro beneficiado o cura de las dichas islas y siendo necessaria la dicha vissita con hazerse de esta manera cesaron los muchos y muy grandes ynconvinientes que se han recrecido y recrecen de yr a Canaria. De todo lo qual siendo Vuestra Alteza servido me offresco a dar bastante ynforma a esta vuestra Corte. Porque suplico a vuestra Aiteza mande que de aquí adelante no se use desta novedad y conviniendo que se haga la dicha visita se cumpla conque la haga el vicario o beneficiado o cura qualquiera de las dichas islas. Para lo qual escribo. 


\section{CONCLUSIONES}

- La población morisca canaria procede, prácticamente en su integridad, de las capturas de esclavos en Berbería.

- El número de esclavos totales, o sea negros y moriscos, que arribaban a las islas, se ha estimado, en media, del orden de 100 anuales a lo largo del siglo XVI.

- La causa de estas capturas estaba en la necesidad de mano de obra que existía en el archipiélago, aunque también en el tráfico comercial con el continente americano. Este último aspecto se sale de los objetivos del presente trabajo.

- Los esclavos moriscos se distinguieron en determinados oficios: transportistas, ganaderos, prenseros, encajadores, etc... En otros oficios, como por ejemplo el trabajo en ingenios azucareros, albañilería, faenas agrícolas o servidumbre, los negros fueron sustituyendo a los moriscos.

- Debido al fenćmeno de los rescates, la población esclava morisca fue poco a poco siendo sustituida por población esclava negra, más dócil y fuerte físicamente. A finales del siglo XVI observamos además un sustancial aumento de las manumisiones de esclavos moriscos, los cuales, a pesar de las dificultades raciales, se integran en la sociedad canaria.

- La acción de la Inquisición canaria contra la herejía mahometana fue intensa, pero de menor dureza que la ejercida en contra de los reos por Judaísmo o Protestantismo. Todas las relajaciones en persona del siglo XVı en Canarias, a excepción de una que recayó en un protestante, se producen sobre reos por Judaísmo. Otras de las condenas más duras que el tribunal inquisitorial canario solia aplicar, aunque también en proporción baja, fueron las de «encierro en convento» y «prohibición de ir a la tierra de herejes". Pues bien, éstas se aplicaron mayoritariamente a luteranos y calvinistas.

- Comparando la frecuencia de las cabalgadas a Berbería en busca de esclavos con la aparición de reos por Mahometismo en los autos de fe de la Inquisición canaria, hemos descubierto una lógica correlación. Pero el fenómeno más interesante es el de la enorme frecuencia de quemas en efigie, frente al tipo de condena más usual en otros tribunales 
inquisitoriales coetáneos, que no suele ser la quema en efigie. La frecuencia de esta condena, casi siempre ligada a reos por Mahometanismo que han "huido" de la persecución inquisitorial, o que simplemente han "huido" para recuperar su antigua fe islámica, aparece asociada al fenómeno de los rescates, en los que un esclavo morisco se canjea por dos o más esclavos negros.

- Hacia el último cuarto de siglo, detectamos protestas de los potentes mercaderes frente a la acción obstruccionista del tribunal inquisitorial. Ambas instancias, cada una de ellas buscando sus específicos 1 intereses, entran, en ocasiones, en colisión. 
Moriscos e inquisición en Canarias durante el siglo XVI

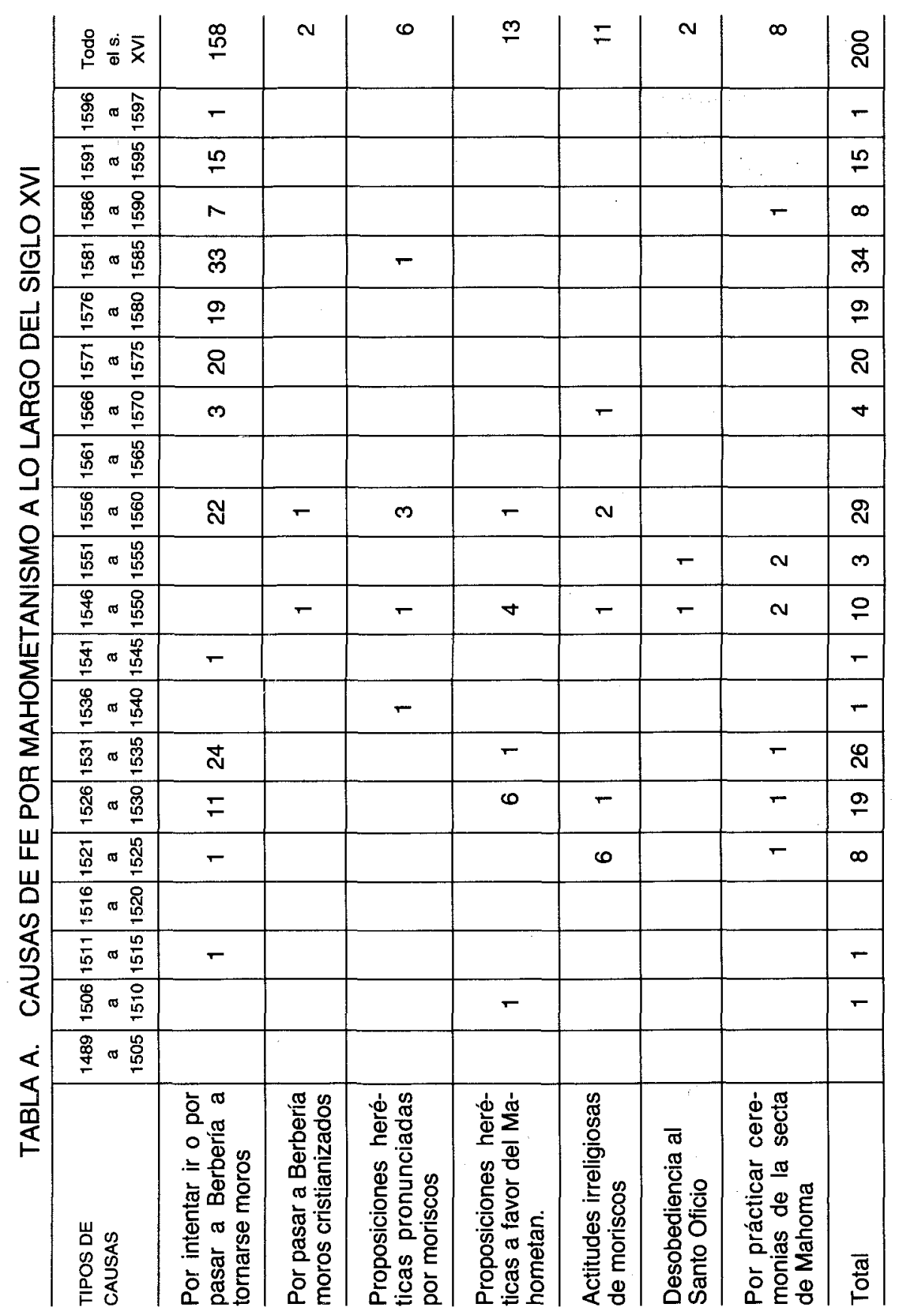


ANDRÉS ACOSTA GONZÁLEZ

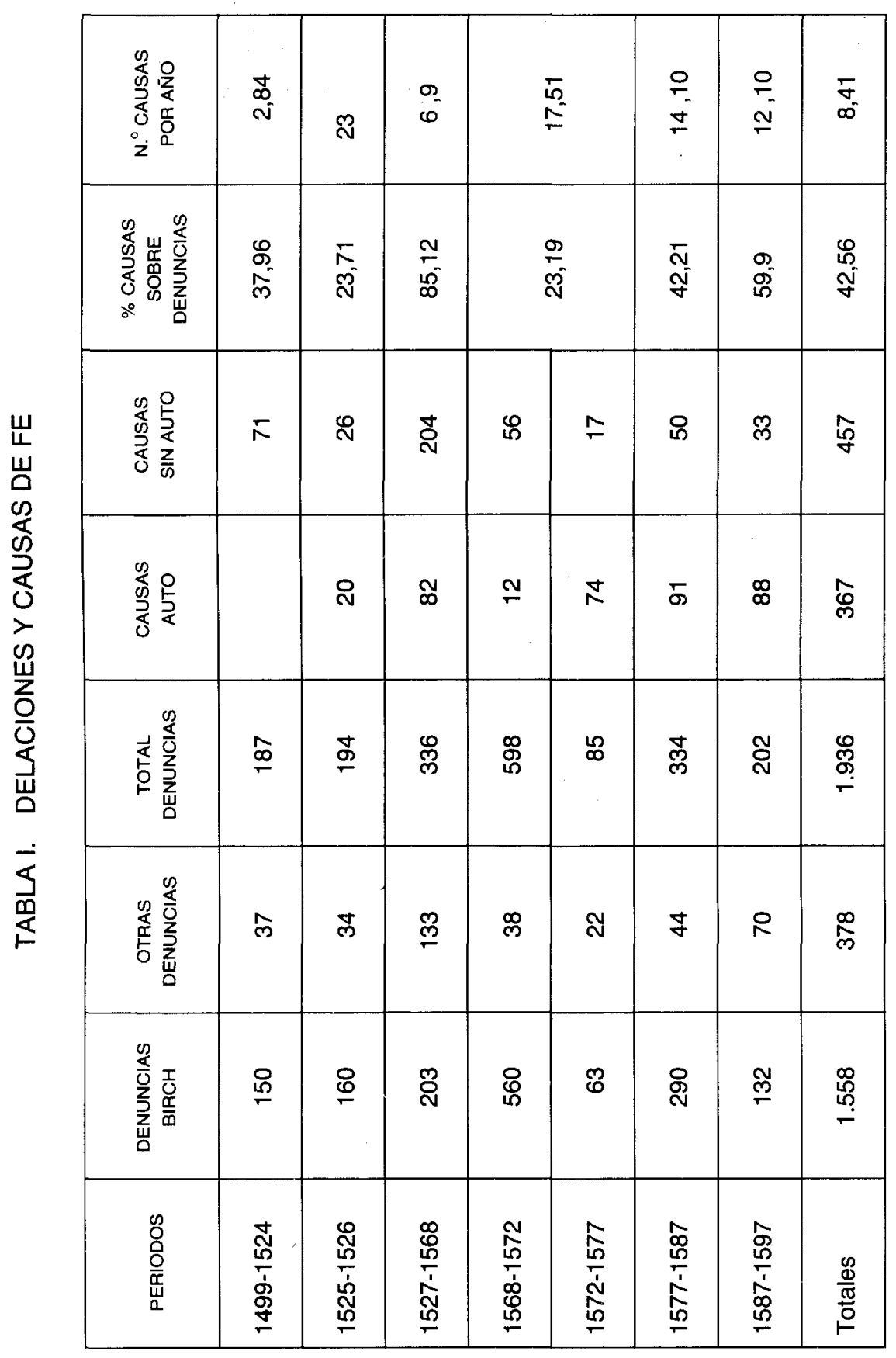


Moriscos e inquisición en Canarias durante el siglo XVI

\begin{tabular}{|c|c|c|c|c|c|c|c|c|c|c|c|}
\hline $\begin{array}{c}1 \wedge x \cdot S \\
7 \exists \text { OaOI }\end{array}$ & & $\mp$ & ङ & ڤે & $\stackrel{m}{q}$ & $\stackrel{\infty}{N}$ & $\mathscr{6}$ & $\nabla$ & $\infty$ & N & స్ \\
\hline$\angle 6 S L \mathrm{e}$ & & in & - & $N$ & - & - & & & & & $\mathscr{0}$ \\
\hline S6S I $\mathrm{e}$ & & $\nabla$ & $\stackrel{\omega}{\leftarrow}$ & $\approx$ & - & $N$ & - & & $\nabla$ & - & 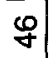 \\
\hline 069le & & $\cong$ & $\infty$ & Nิ & & & $\nabla$ & $N$ & $m$ & - & ชิ \\
\hline S8S $\mathrm{e}$ & & $m$ & $m$ & $\hat{m}$ & & $N$ & $m$ & $N$ & $\infty$ & $\sim$ & $\hat{\infty}$ \\
\hline O8GI & & & O & $\bar{N}$ & & $N$ & & & $\nabla$ & & $\mathscr{q}$ \\
\hline SLGL e & & $\omega$ & 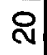 & $\mp$ & - & 10 & $N$ & & $m$ & & $\mathscr{q}$ \\
\hline $0 \angle S \perp e$ & & & $m$ & $\bar{m}$ & $m$ & $m$ & $\infty$ & & $\stackrel{10}{\square}$ & $\omega$ & 8 \\
\hline sgal e & & 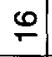 & & - & $N$ & & & & & 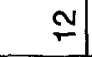 & $\bar{m}$ \\
\hline O9g L $\mathrm{e}$ & & $\nabla$ & $\stackrel{ }{\circ}$ & 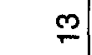 & & - & - & & & & $\mathscr{L}$ \\
\hline SGSL & & & $m$ & 운 & $N$ & $N$ & . & & - & & $\stackrel{\infty}{\Gamma}$ \\
\hline OGg। & & & 음 & $\stackrel{m}{-}$ & $\nabla$ & $\nabla$ & - & & $N$ & & ষे \\
\hline StGLe & & & - & $N$ & & & & & - & & $\sigma$ \\
\hline OtS & & & - & $N$ & & & & & & & $m$ \\
\hline SESLe & $\infty$ & & $\stackrel{N}{N}$ & స్ & $\infty$ & - & - & & $\nabla$ & & $\mathscr{\mathscr { C }}$ \\
\hline OEG $\mathrm{e}$ & 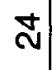 & 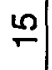 & 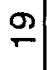 & \pm & $N$ & - & $N$ & & $\stackrel{\infty}{-}$ & & 8 \\
\hline GZSL $e$ & $\omega$ & & $\infty$ & $\lambda$ & o) & $\nabla$ & g & & $\infty$ & & $\bar{\infty}$ \\
\hline OZSL & - & & & - & & & & & & & $\mathbf{v}$ \\
\hline SIGLe & & & - & & & & $N$ & & & & $m$ \\
\hline $0 / G \mid \mathrm{e}$ & - & & & - & - & & - & & & & $\forall$ \\
\hline sosl-68tL & $N$ & & & $\sim$ & $\nabla$ & & - & & & & $\sigma$ \\
\hline 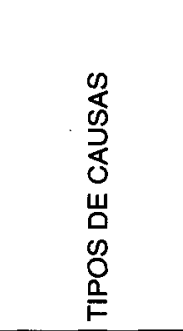 & $\begin{array}{c}\vdots \\
\vdots \\
0 \\
\frac{0}{5} \\
\frac{5}{5} \\
\supset\end{array}$ & 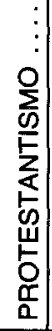 & $\begin{array}{l}\frac{0}{\sum} \\
\frac{0}{2} \\
5 \\
\frac{1}{2} \\
\frac{0}{1} \\
\frac{5}{\Sigma}\end{array}$ & 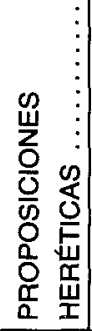 & 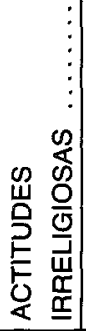 & 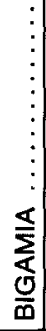 & 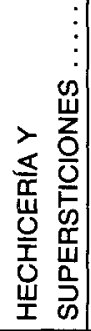 & 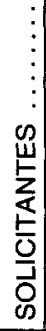 & 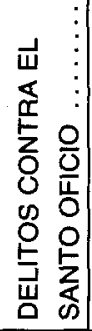 & 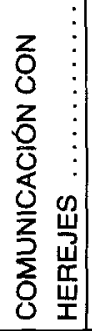 & 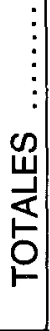 \\
\hline
\end{tabular}


ANDRÉS ACOSTA GONZÁLEZ

TABLA III. TIPOS DE DELACIONES

\begin{tabular}{|l|c|c|c|c|}
\hline & AUTODELAC. & DELACIONES & PESQUISAS & SIN DETERM. \\
\hline $1489-1526$ & 15 & 61 & 13 & 22 \\
\hline a 1568 & 28 & 12 & 137 \\
\hline a 1572 & 2 & 55 & 7 & 6 \\
\hline a 1576 & 2 & 14 & 8 & 61 \\
\hline a 1587 & 8 & 49 & 3 & 81 \\
\hline a 1597 & 2 & 40 & 10 & 69 \\
\hline TOTALES & 29 & 247 & 53 & 376 \\
\hline
\end{tabular}

TABLA IV. CASOS DE TORMENTO

\begin{tabular}{|c|c|c|l|}
\hline & CUMPLIDO & AMENAZA & \multicolumn{1}{|c|}{ CAUSAS } \\
\hline $1489-1526$ & 1 & 1 & $\begin{array}{l}\text { Judaísmo } \\
\text { Brujeria }\end{array}$ \\
\hline a 1568 & 2 & 6 & Judaísmo \\
\hline a 1576 & 2 & 4 & $\begin{array}{l}\text { Mahomet. } \\
\text { Luteranismo } \\
\text { Proposición }\end{array}$ \\
\hline a 1597 & 2 & 3 & $\begin{array}{l}\text { Calvinismo } \\
\text { Luteranismo }\end{array}$ \\
\hline TOTALES & 7 & 14 & \\
\hline
\end{tabular}


TABLA V. TIPOLOGÍA DE LAS CONDENAS

\begin{tabular}{|c|c|c|c|c|c|}
\hline CONCEPTOS & $\begin{array}{l}1499- \\
1526\end{array}$ & a 1548 & a 1574 & a 1581 & a 1597 \\
\hline Relajación en efigie. & 1 & 45 & 47 & 52 & 30 \\
\hline $\begin{array}{l}\text { Relajación en per- } \\
\text { sona } \ldots \ldots \ldots \ldots \ldots . .\end{array}$ & & 7 & & & 1 \\
\hline Cárcel & 15 & 2 & 10 & 1 & 15 \\
\hline Confiscación bienes. & 2 & 13 & 4 & 4 & 49 \\
\hline Destierro .. & 4 & & 9 & 3 & 26 \\
\hline Vergüenza pública & 10 & 15 & 16 & 12 & 14 \\
\hline Sanbenito & 8 & 10 & 4 & 1 & 1 \\
\hline $\begin{array}{l}\text { Encierro en con- } \\
\text { vento } \ldots \ldots \ldots \ldots \ldots . .\end{array}$ & & 2 & 4 & 5 & 54 \\
\hline $\begin{array}{l}\text { Prohibir ir a tierra } \\
\text { herejes } \ldots \ldots \ldots \ldots \ldots\end{array}$ & & & & & 56 \\
\hline Azotes & 3 & & 12 & 9 & 25 \\
\hline Soga al cuello & 2 & & 3 & 10 & 7 \\
\hline Mordaza & 2 & 2 & 3 & 3 & 11 \\
\hline Galeras & & 1 & 2 & 1 & 13 \\
\hline $\begin{array}{l}\text { Penitencias religio- } \\
\text { sas } \ldots \ldots \ldots \ldots \ldots \ldots\end{array}$ & 9 & 10 & 36 & 41 & 110 \\
\hline Reprehensión & 4 & 9 & 6 & & 42 \\
\hline Reconciliac. & 10 & 48 & 32 & 3 & 37 \\
\hline $\begin{array}{l}\text { Despedida y sus- } \\
\text { pensión } \ldots \ldots \ldots \ldots \ldots\end{array}$ & & 1 & & & 1 \\
\hline Absolución & 1 & 15 & 4 & 1 & 13 \\
\hline Pagos al Sto. Oficio. & 6 & 2 & 43 & 5 & 23 \\
\hline Sin determ. & 58 & 89 & 64 & 9 & 1 \\
\hline
\end{tabular}


CUADRO VI. QUEMAS EN ESTATUA POR MAHOMETANISMO

\begin{tabular}{|c|c|c|c|}
\hline AUTOS & $\begin{array}{l}\text { Quemados } \\
\text { en estatua }\end{array}$ & $\begin{array}{c}\text { Otras } \\
\text { condenas }\end{array}$ & Observac. \\
\hline $1489-1526$ & 1 & & Comercian. \\
\hline Auto 1526 & & 5 & Esclavos \\
\hline a 1534 & 6 & 6 & $\begin{array}{c}11 \text { esclavos } \\
1 \text { herrero }\end{array}$ \\
\hline Auto 1534 & & 24 & Esclavos \\
\hline a 1548 & & 2 & Esclavos \\
\hline Auto 1548 & & 3 & Esclavos \\
\hline a 1557 & & 2 & Esclavos \\
\hline Auto 1557 & 17 & 4 & Esclavos \\
\hline Auto 1569 & 3 & & $\begin{array}{l}2 \text { esclavos } \\
1 \text { comerc. }\end{array}$ \\
\hline a 1574 & & 8 & Esclavos \\
\hline Auto 1574 & 3 & 9 & Esclavos \\
\hline Auto 1576 & 16 & 3 & Esclavos \\
\hline Auto 1581 & 31 & 2 & $\begin{array}{l}1 \text { comerc. } \\
30 \text { esclavos }\end{array}$ \\
\hline Auto 1587 & 4 & 6 & 8 esclavos \\
\hline a 1591 & & 1 & 1 esclavo \\
\hline Auto 1591 & 15 & & Esclavos \\
\hline Auto 1597 & & 1 & Esclavos \\
\hline Totales & 96 & 76 & \\
\hline
\end{tabular}




\section{GRAFICO I. DISTRIBUCIÓN GENERAL DELACIONES Y CAUSAS}

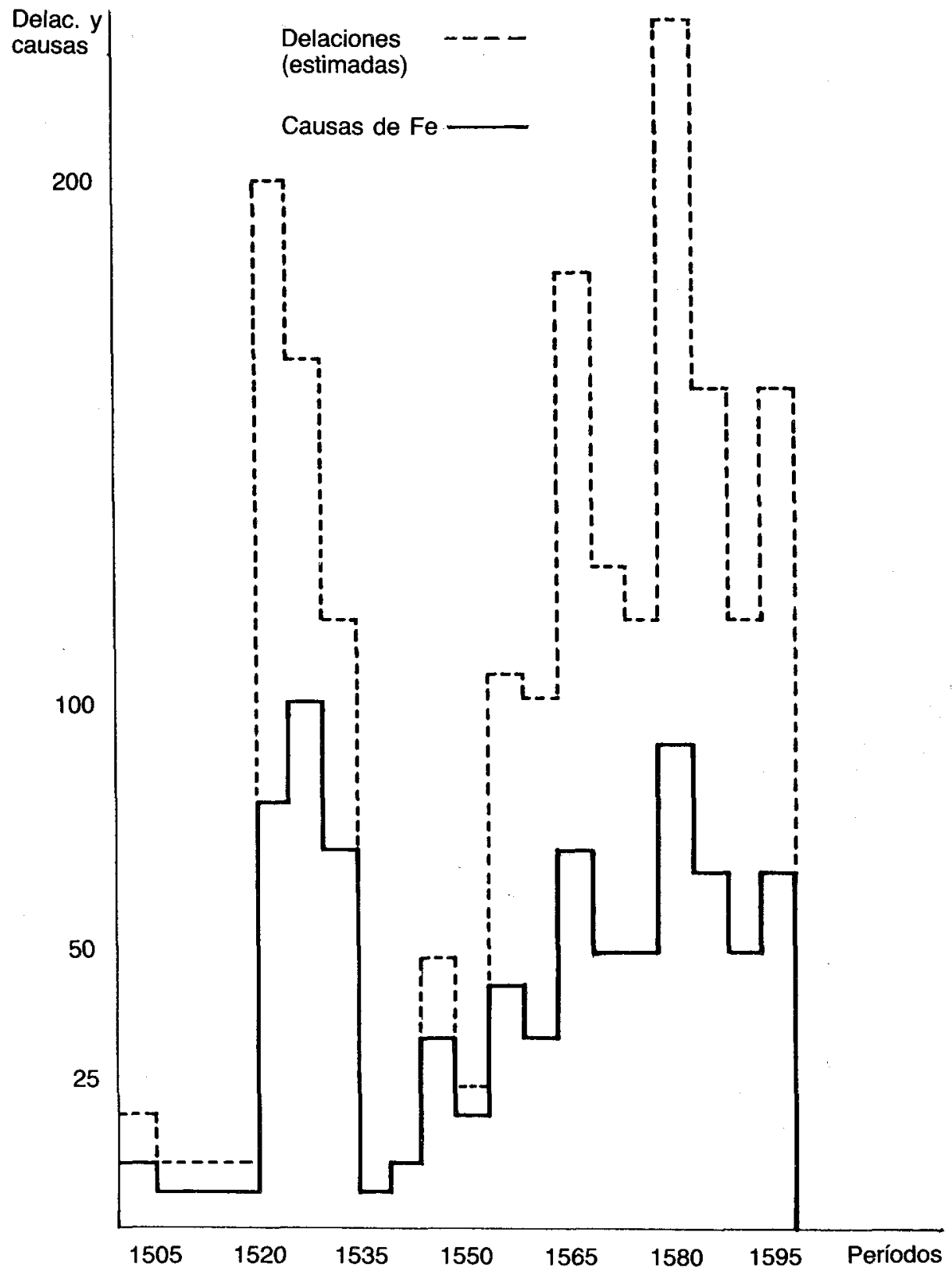


GRAFICO II. DISTRIBUCIONES CAUSAS DE FE

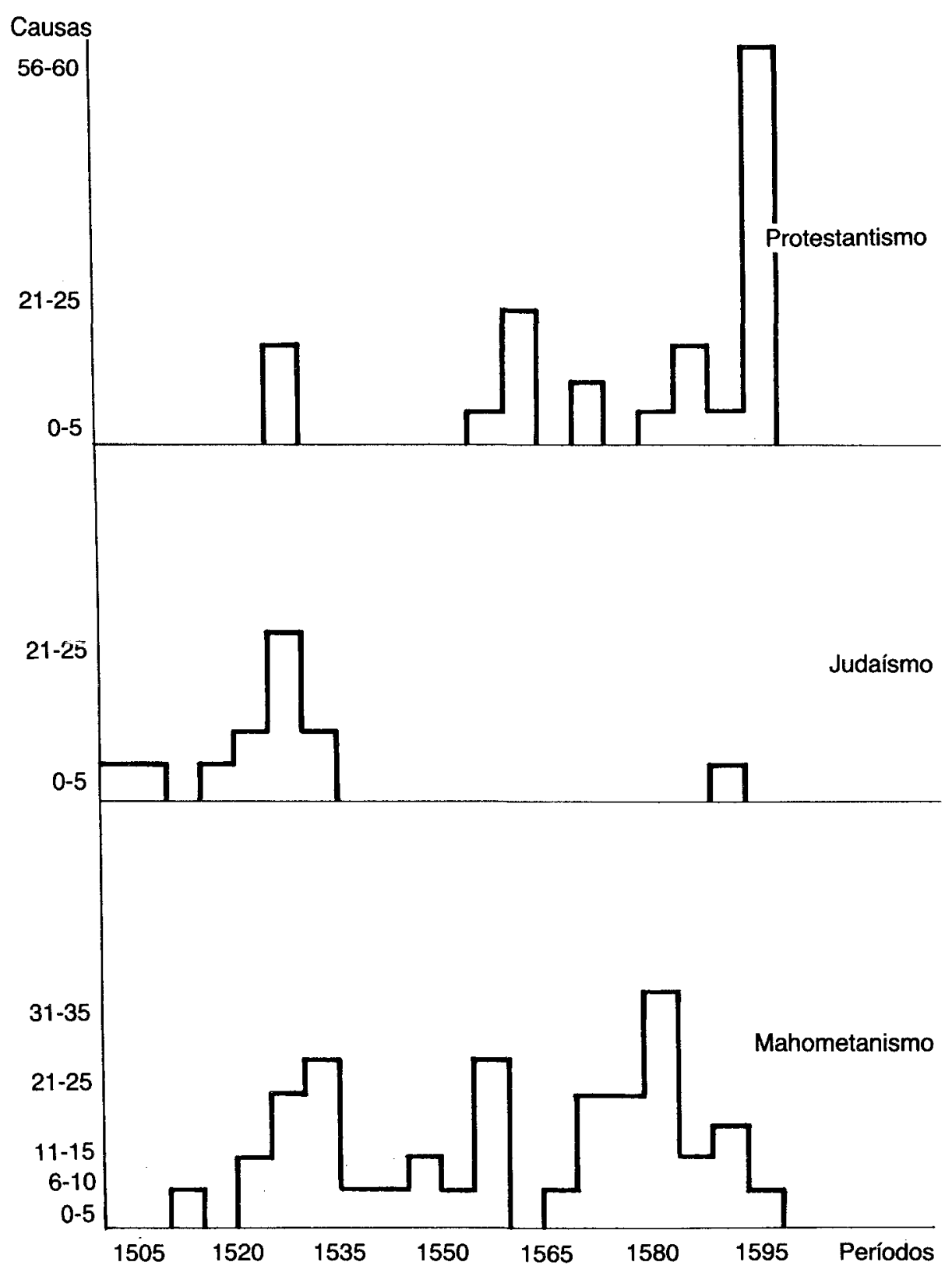




\section{GRAFICO III. DISTRIBUCIONES CAUSAS DE FE}

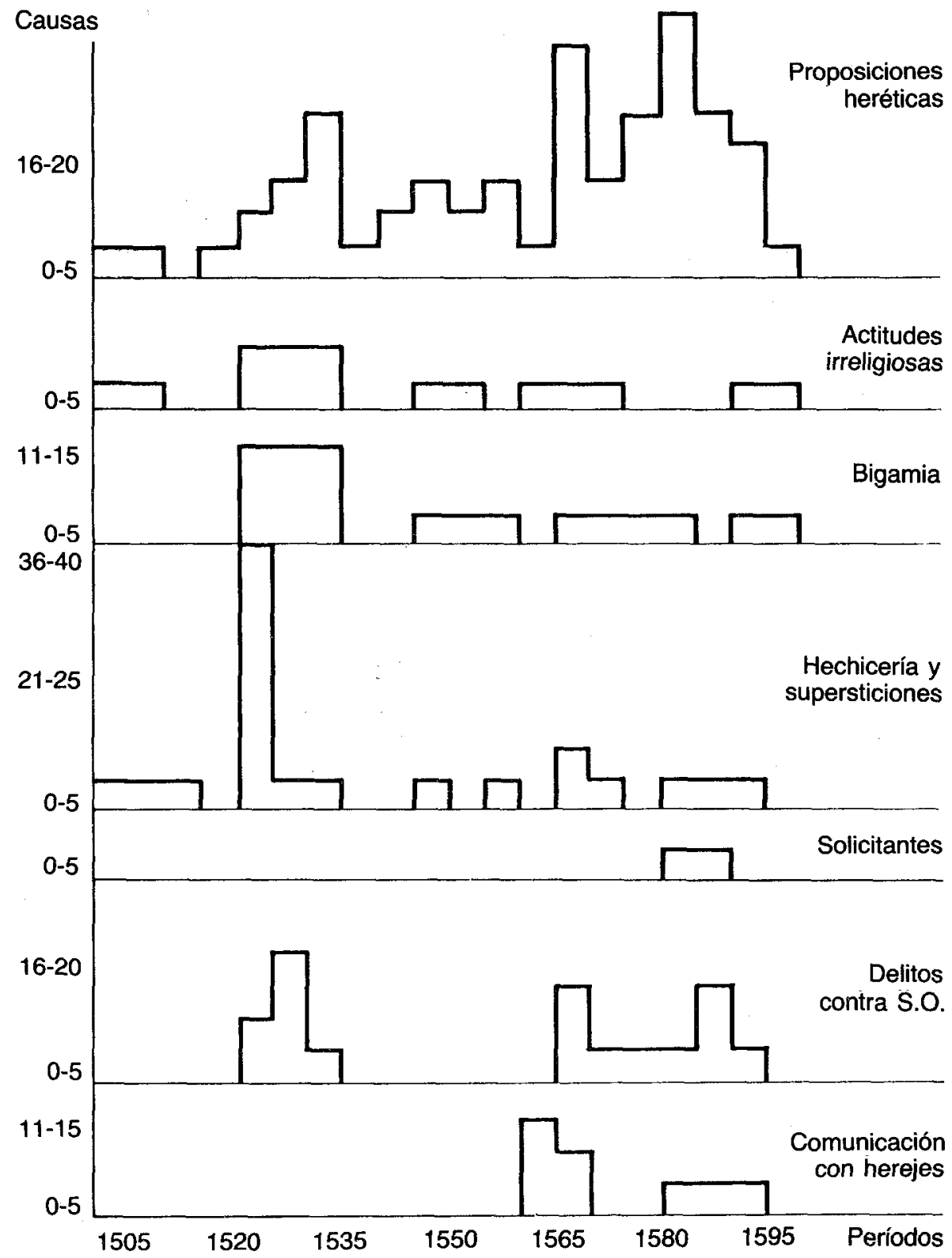

